\title{
Evaluation of Fatigue Damage in Adhesive Bonding: \\ Part 2: Single lap joint
}

\author{
M.M. Abdel Wahab ${ }^{1, *}$, I. Hilmy ${ }^{2}$, I.A. Ashcroft ${ }^{3}$ and A.D. Crocombe ${ }^{2}$ \\ ${ }^{1}$ Department of Mechanical Construction and Production, Faculty of Engineering, Ghent \\ University, B-9000 Gent, Belgium \\ ${ }^{2}$ Faculty of Engineering and Physical Sciences, University of Surrey, Guildford, Surrey, \\ GU2 5XH, UK \\ ${ }^{3}$ Department of Mechanical Engineering, Loughborough, Leicestershire, LE11 3TU, UK
}

*Corresponding author: Prof. Dr. Ir. Magd Abdel Wahab, e-mail: magd.wahab@ugent.be

Abstract: Damage parameters for crack initiation in Single Lap Joint (SLJ) are determined by combining continuum damage mechanics, Finite Element Analysis (FEA) and fatigue experimental data. Even tough SLJ has a simple configuration; the stresses in the adhesive region are quite complex and exhibit a multi-axial state. Such a condition leads to the need to introduce a general value of triaxiality function in the damage evolution law rather than using a triaxiality function equals to unity as in the case of uniaxial stress state, e.g. bulk adhesive test specimen presented in part 1 of this paper. The effect of stress singularity due to the presence of corners at edges also contributes to the complex state of stress and the variability of triaxiality function along the adhesive layer in SLJ. The damage parameters $A$ and $\beta$ determined in Part 1 for bulk adhesive are now extended to take into account the multi-axial stress state in the adhesive layer as calculated from FEA. 
Keywords: Continuum Damage Mechanics, Low Cycle fatigue, Finite Element Analysis, Single Lap Joint, Stress Triaxiality, Crack Initiation, lifetime prediction

\section{Introduction}

Nowadays, the use of adhesive bonding has gained more popularity in almost every sector ranging from home appliance to large industry. In aircraft industry, adhesive bonding is widely used and becomes an alternative to conventional joining techniques such as riveting and welding. In aircraft structures, adhesive joints are used for attaching stringers to fuselage and wing skins to stiffen the structures against buckling. It is also used to manufacture lightweight structures of metal honeycomb cores inside metal skins for the flight control component structures, e.g. elevators, ailerons, spoilers, etc.

The analytical development of single lap joint was started from a simple classical static model. Adherends were considered as rigid bodies, while adhesive was considered as a linear elastic body. It was assumed that adhesive will deform only in shear. With this assumption, the shear stress is constant along the contact surfaces. The limitation of this technique is that shear stress distribution within the adhesive region cannot be calculated.

Volkersen [1] introduced new assumptions in which both substrates and adhesive elastically deformed. It was further assumed that adherend deformed in tension while adhesive deformed in shear. With these assumptions, consequently, shear stress along the interface is not constant. The drawback of this model is that the effect of bending moment was not taken into account. Since the applied load from both ends of substrates is not colinear, the offset between the two loads causes bending moment. As a result, bending stresses will take place, causing peel stresses at the overlap ends. Goland and Reissner [2] have improved Volkersen's model, by considering both shear and peel stresses. Compared to Vokersen's formula, Goland-Reissner' solution was more accurate. It was 
found later that sharp tip at the corner would raise stress singularity. Theoretically, the elastic stresses and strains at this point will be infinite. This phenomenon was not included in Goland-Reissner's formula. Hart-Smith [3] introduced a new model of a single lap adhesive joint in which substrates and adhesive were separately modelled. Substrates were modelled as a beam on elastic foundation. As a consequence, the influence of large displacement was neglected. Frostig et al. [4] proposed a new formulation using Closed-Form High-Order (CFHO) theory, in which formula for single lap joint based on variational principle was developed. The overlap region was modelled using concept of CFHO theory developed for sandwich panels.

Single-lap joint is considered to be the simplest joint configuration. Even tough it is simple in configuration, the stress-strain state that occurs in the adhesive layer and along the substrate/adhesive interface is quite complex because of the mixture of peel stress, shear stress and hydrostatic stress (which is defined as the mean normal stress [5]). In order to accurately predict the performance of an adhesive joint using Finite Element Analysis (FEA) the following information is required:

- Mechanical properties for adhesive and substrates,

- Dimensions of the joint,

- Constraints and loads,

- Failure criteria for both adhesive and substrates.

Many researchers have performed finite element analysis of single lap joint using twodimensional and three-dimensional models. Single lap adhesive joint with composite substrates, has been modelled by Magalhaes et al. [6] using two-dimensional elements to model substrates and adhesive layer and interface elements to model the 
substrate/adhesive interface. Adams and Peppiatt [7] have studied the effect of fillet on the stresses in single lap joints using two-dimensional finite element analyses. They found that using a fillet reduced the magnitude of principal stress in the adhesive layer. Single lap joint with aluminium alloy and mild steel substrates, has been modelled by Liu and Sawa [8]. They proposed analytical solution using elastic contact theory and elastoplastic finite element analysis. They found that the analytical solution provided accurate results. Goncalves et al. [9] has analysed single lap joint using three-dimensional model and has used interfacial elements to represent contact surface between adhesive and substrates. Crocombe [10] has proposed several material models that can be used to model adhesives in finite element analysis.

When using finite element analysis, model can be generated for complex geometries and configurations. With the advance of Computer Aided Design (CAD), nowadays every details of the geometry can be followed and accurately modelled. For different boundary conditions, a finite element model of a structure can produce different results. Therefore, finite element analyses need to be validated with experimental data and/or analytical solution. Different boundary conditions of single lap joint model according to Wahab [11] and Wahab et al [12] have been used for single lap adhesive joints. In reference [11] a simply supported boundary condition has been used while in reference [12] fixed ends have been used. Another model has been proposed by Dean and Crocker [13] where fillets were used at the edges of adherends and adhesive in order to reduce the effect of singularity.

It is evident from the literature that much effort has been directed to overcoming the difficulties that are caused by the stress singularity in a bi-material system. Many of 
the failure criteria are based on simplified analytical solution and make use of the maximum shear stress [14] or peel stress [3]. Many researchers proposed the use of stress/strain generated from analyses like FEA that include the effect of the singularity. As the stress is singular it is necessary to use a characteristic distance from the point of singularity, e.g. John et al [15] and Crocombe et al [16]. The disadvantages of this technique are the lack of physical significance and the difficulties associated with choosing the characteristic distance. Anderson and DeVries [17] introduced another technique based on fracture mechanics, known as 'inherent flaw method'. In this approach, a small crack (usually a fraction of $\mathrm{mm}$ ) is initiated at the singular point and strain energy release rates are calculated. The size of this crack (inherent flaw), $a_{0}$, has to be determined experimentally by testing several specimens with different crack lengths and interpolating $a_{o}$ using the load of the uncracked specimen. The drawback of this method is the need of a considerable number of experiments in order to determine the inherent flaw size and the lack of accuracy in introducing cracks that are fractions of a millimetre. Further, it may not be considered appropriate to represent an uncracked specimen by a cracked one. The use of a stress singularity parameter, equivalent to stress intensity factor in a cracked body, at the bi-material corner point was investigated by Groth and Brottare [18], Hattroi et al [19] and Lefebvre and Dillard [20]. However, the shortcomings of this stress singularity parameter are its dependence on the strength of the singularity and its variation with mode mixity. Several studies have been devoted to characterise the stress singularities in bi-material [21-23]. 


\section{Finite Element Model of SLJ}

In this paper, several assumptions for the finite element analysis of a single lap joint have been made in order to achieve a simple and effect simulation. Two dimensional plain strain element, Plane82 from ANSYS element library, has been used for both substrates and adhesive layer. This is a two dimensional higher order element, which is shown in Figure 1. With the presence of mid-side nodes in the element edges, this element has many advantages including: a) more accurate results for mixed (quadrilateral-triangular) automatic meshes and b) irregular shapes can be tolerated without much loss of accuracy [24].

The geometry of the single lap joint is shown in Figure 2. The specimen dimensions and boundary conditions are similar to the one used in the fatigue experiments performed by Solana [25]. In this model, adherends were made from 2014T6 Aluminium with Young's Modulus $E=70000 \mathrm{~N} / \mathrm{mm}^{2}$ and Poisson's Ratio $v=0.33$. Adhesive was made from FM-73 ${ }^{\text {TM }}$ film-form from Cytec. Material properties of FM-73 are as follows: Young's Modulus $E=1211 \mathrm{~N} / \mathrm{mm}^{2}$ and Poisson's Ratio $v=0.38$ [25]. The model uses multilinear kinematic hardening material with stress-strain curve as shown in Figure 3. The stress-strain curve in Figure 3 was experimentally determined in Part 1 of this paper using bulk adhesive test specimens.

Singularity corners are points where the magnitudes of elastic stress increased theoretically to infinity. Singularity usually occurs at the tip or corner where there is a sharp change in geometry. Points that possess stress singularity in a single lap joint are shown in Figure 4. 
In order to obtain more accurate data near singularity tips or corners, very fine mesh near those points is necessary. As the mesh would be mapped on areas, the single lap joint was divided into several areas with smaller ones near the singularity tips (Figure 5(a)). With such a discretisation, customize meshing rather than automatic meshing was generated. The benefit of this meshing technique is that the element size can be easily controlled by defining the number of elements on each area. Implementation of the final FE mesh is shown in Figure 5(b).

Because the element size near singularity tips will contribute directly to the computational time, it is important to compromise between accuracy and CPU time. Because of the stress singularity at the tips, the stresses are calculated at a distance of $0.005 \mathrm{~mm}$ from the tips. However, element size near the tips should be selected so that the stresses are accurate enough at that distance. Therefore, analyses with different element sizes have been performed in order to determine the largest element size that would provide accurate stresses at $0.005 \mathrm{~mm}$ near the singular tips. This element size would be used for all other finite element analyses with different loads. The study of the effect of element size will be focused near the singular points. Three paths located at singular points have been defined to record the stresses as shown in Figure 6. It should be noted that only one path per singular point is required to study the convergence at each point, i.e. one path would be enough for such a study.

Figure 7 shows the effect of element size on von Mises stress. Convergence of stress at a distance of $0.005 \mathrm{~mm}$ from Tip 1 is achieved for element size of $3.25 \mu \mathrm{m}$. Therefore, this element size will be used for the remaining FE analyses. 
Figures 8 and 9 show von Mises stresses along Paths 2 and 3, respectively. From Figures 7, 8 and 9, it can be seen that tips 2 and 3 are less sensitive to element size than tip 1. Furthermore, as expected, the stress at tip 1 is larger than that at tips 2 and 3 . This is mainly due to the considered load configuration of the single lap joint. Therefore, in the present analysis, tips 2 and 3 are less important than tip 1.

\section{Validation of the Finite Element Results}

The strain calculated from the finite element analysis of the single lap joint will be compared with that obtained from the fatigue experiments reported in Solana [25]. The fatigue tests were carried out in room temperature using an Instron machine 1341 available in the Adhesives and Composites research laboratory in the University of Surrey. The test frequency was $5 \mathrm{~Hz}$ and the stress amplitude ratio was 0.1 . The strain was measured using backface strain technique, in which strain gauges were placed on the top and bottom surfaces of the substrates in the overlap region. A change in the measured strain would indicate initiation of a crack at the overlap edges. Figure 10(a) shows the position of the strain gauges used in the fatigue experiments. A total of six strain gauges were placed on the overlap edges; three on the top surface (SG1, SG2 and SG3) and three on the bottom surface (SG4, SG5 and SG6). Table 1 presents the fatigue loads as a percentage of static failure load, minimum and maximum amplitudes, number of cycle to failure, $N_{f}$ and failure strain.

In Figure 10(b), taken from reference [25], strain was plotted as a function of number of cycles for the case of load level equivalent to $60 \%$ of the static failure load, which is equal to $6.4 \mathrm{kN}$. The rapid change in strains indicates the initiation and 
propagation of damage under the strain gauges. In order to validate the FE model, the strain calculated from FEA under static load will be compared to the measured strain at the peak of the first fatigue cycle. It is assumed that the initial strains occur at the peak of the first cycle are identical to the strains caused by static load. The initial strain range measured at the peak of the first fatigue cycle at the strain gauges' position (three strain gauges) shown in Figure 11 (a) [25] was in the range of -0.00027 to -0.00060 . The strain distribution from FE analysis is shown in Figure 11 (b). At the same strain at gauges' position in Figure 11(a), the FE strain is equal to -0.000565 , which is within the range of the measured strains. Therefore, it is concluded that the finite element model is valid and can be used for further analyses.

\section{Calculation of Damage Parameters}

In order to apply the damage evolution law to the single lap joint, two types of stress are required from the finite element analysis (see later Equations (5) and (6)); namely von Mises equivalent stress and Hydrostatic Stress. von Mises stress is defined as follows [26]:

$$
\sigma_{e q}=\sqrt{\frac{\left(\sigma_{1}-\sigma_{2}\right)^{2}+\left(\sigma_{2}-\sigma_{3}\right)^{2}+\left(\sigma_{3}-\sigma_{1}\right)^{2}}{2}}
$$

Where $\sigma_{1}, \sigma_{2}$ and $\sigma_{3}$ are the principal stresses. Principal stresses are stresses that occur when elements are in pure tension and/or pure compression state, e.g. no shear deformation. An example of a contour plot of von Mises stress in the adhesive layer is shown in Figure 12. Maximum value is denoted as $M X$ and located at Tip 1 and minimum value is denoted as $M N$ and located at Tip 2. Contour legend shows stress values range from 2.481 $\mathrm{MPa}$ to $43.936 \mathrm{MPa}$. 
Hydrostatic stress is stress that caused element to change its size (shrink or grow due to principal stresses) without changing its shape (no shear stresses). Hydrostatic stress is defined as follows [27]:

$$
\sigma_{H}=\frac{\sigma_{1}+\sigma_{2}+\sigma_{3}}{3}
$$

Figure 13 shows an example of a contour plot of hydrostatic stress in the adhesive layer. As it will be shown later in this section, the triaxiality function is required for the implementation of the damage model (see Equations (5) and (6)). The triaxiality function, which is defined as the square of the ratio between the damage equivalent stress $\sigma^{*}$ and the von Mises equivalent stress $\sigma_{e q}$, i.e. $R_{v}=\left(\frac{\sigma^{*}}{\sigma_{e q}}\right)^{2}$. The triaxiality function can be written as follows [28]:

$$
R_{v}=\frac{2}{3}(1+v)+3(1-2 v) T_{x}^{2}
$$

Where $v$ is Poisson's Ratio and $T_{x}$ is the triaxiality ratio, which is defined as the ratio between the hydrostatic stress $\sigma_{H}$ and von Mises stress $\sigma_{e q}$, i.e.:

$$
T_{x}=\frac{\sigma_{H}}{\sigma_{e q}}
$$

The triaxiality function provides a mean to evaluate the multi-axial stress state. For example, in a uniaxial test the hydrostatic stress is equal to the von Mises stress and therefore the triaxiality ratio is equal to 0.333 and the triaxiaxlity function is equal to 1 . In case of multi-axial stresses, the triaxiality ratio becomes larger than 0.333 and the triaxiality function becomes larger than 1 . 
Since the hydrostatic stress and von Mises equivalent stress values are available in ANSYS, Contour of triaxiality function, $R_{v}$ can be calculated. An example of a contour plot of triaxiality function is shown in Figure 14. Both hydrostatic and von Mises stresses are saved in a table called Element Table, a facility available in ANSYS. Using Element Table facility, several mathematical manipulations of the stored data can be performed. The mathematical functions Exponentiation, Multiply and Add are used to apply Equation (3) for the calculation of the triaxiality function.

Lemaitre [29] proposed that in the field of damage mechanics, stress Triaxiality, not von Mises equivalent stress, governs the damage process. This is to say, to analyze the mechanical response of the construction with high constraint, such as the solder joints in electronic packaging where a thin ductile layer of solder alloy constrained by the surrounding rigid elastic substrates, the concept of stress triaxiality should be introduced $[30,31]$. This is because of the multi-axial stress state in such a configuration.

Single lap joints have more complex multi-axial stress state than bulk adhesives. This is because in bulk adhesive under uniaxial tension, triaxiality function $\left(R_{v}\right)$ is equal to one (uni-axial stress state), which is not the case for single lap joints under simple tension load. In order to extract the damage parameters from the FEA of the single lap joint taking into account different triaxiality functions along the adhesive layer, further derivation of the damage model presented in part 1 of this paper is required.

Derivation to find the damage parameters $A$ and $\beta$ from damage evolution law is based on assumption that global damage will occur in the adhesive layer at final failure. Full derivation of damage model has been performed by Wahab et al. [28], from which the damage evolution law is given by: 


$$
D=1-\left[1-A(\beta+m+1)\left(\Delta \sigma_{e q}\right)^{\beta+m} R_{V}^{\beta / 2} N\right]^{\frac{1}{\beta+m+1}}
$$

Where $D$ is the damage variable, $N$ is the number of cycles, $\Delta \sigma_{e q}$ the range of vonMises stress, $R_{V}$ the triaxiality function, $m$ the power constant in Ramberg-Osgood equation, and $A$ and $\beta$ are damage parameters to be determined experimentally. As mentioned in Part 1 of this paper, in case of constant displacement amplitude test, the stresses decrease as function of number of cycles and $\Delta \sigma_{e q}$ should be replaced by $\Delta \sigma_{e q}^{*}$, which is von-Mises stress range for virgin material or at stabilization of harding. At failure, $N=N_{f}$, where $N_{f}$ is the number of cycles to failure, and $D$ becomes 1 (fully damaged state) so that fatigue life can be predicted as [28]:

$$
N_{f}=\frac{\Delta \sigma_{e q}^{-\beta-m} R_{v}^{-\frac{\beta}{2}}}{A(\beta+m+1)}
$$

As $\Delta \sigma_{e q}^{-\beta-m}$ is equivalent to $\Delta \sigma_{e q}^{-\beta} \Delta \sigma_{e q}^{-m}$, Equation 6 can be re-arranged as:

$$
N_{f}=\frac{1}{A(\beta+m+1)} \Delta \sigma_{e q}^{-\beta} \Delta \sigma_{e q}^{-m} R_{v}^{-\beta / 2}
$$

The term $\Delta \sigma_{e q}^{-\beta} R_{v}^{-\beta / 2}$ is equivalent to $\left(\Delta \sigma_{e q}^{2} R_{v}\right)^{-\beta / 2}$ i.e:

$$
N_{f}=\frac{1}{A(\beta+m+1)}\left(\Delta \sigma_{e q}^{2} R_{v}\right)^{-\beta / 2} \Delta \sigma_{e q}^{-m}
$$

Re-arrenging Equation 8, gives:

$$
N_{f} \Delta \sigma_{e q}^{m}=\frac{1}{A(\beta+m+1)}\left(\Delta \sigma_{e q}^{2} R_{v}\right)^{-\beta / 2}
$$

From the stress-strain curve, the power constant $m$ is known, from fatigue test, $N_{f}$ is known; from FEA, $\Delta \sigma_{e q}$ and $R_{v}$ for all adhesive elements are known, thus the only 
unknown parameters in Equation 9 are A and $\beta$. Let $X_{V A R}=\Delta \sigma_{e q}^{2} R_{v}$ and $Y_{V A R}=N_{f} \Delta \sigma_{e q}^{m}$, Equation 9 can be simplified in a polynomial form as:

$$
Y_{V A R}=\frac{1}{A(\beta+m+1)}\left(X_{V A R}\right)^{-\beta / 2}
$$

Using logarithmic form, Equation 10 is re-written as:

$$
-\ln \left(Y_{V A R}\right)=\ln [A(\beta+m+1)]+\frac{\beta}{2} \ln \left(X_{V A R}\right)
$$

which is an equation of line that has the following simple form:

$$
y=C_{1}+C_{2} x
$$

Comparing Equation 11 to Equation 12, $y=-\ln \left(Y_{V A R}\right), x=\ln \left(X_{V A R}\right), C_{2}=\frac{\beta}{2}$ is a gradient and $C_{1}=\ln [A(\beta+m+1)]$ is a constant.

By fitting the finite element results to Equation (12), $C_{1}$ and $C_{2}$ can be found. The procedure above is presented in the flow chart shown in Figure 15.

\section{Implementation of Damage Parameter Calculation Flowchart}

Implementation of the flowchart for the damage parameters calculation is presented in this section for load level of $30 \%$ of the static failure load. From finite element analysis, von Mises stresses and hydrostatic stresses, presented earlier in section 4, are directly obtained and are shown in Figures 12 and 13, respectively. From Figure 13, it is shown that high hydrostatic stresses are located near Tip 1 while low hydrostatic stresses are located inside the overlap area. Using element table, both results are saved and used for the next calculations. 
In the next step, the triaxiality ratio (Equation 4) and square of the triaxiality ratio are calculated, from which the triaxiality function $\left(R_{v}\right)$ is calculated using Equation 3 and is shown in Figure 14. The minimum values of $R_{v}$ as shown in the legend of Figure 14 are related to state of uni-axial stress (minimum average $R_{v}=\frac{0.922+1.267}{2} \cong 1$ ). High values of $R_{\nu}$ are located near singularity at Tip 1.

The next calculations are concerned with the square of von Mises equivalent stress and von Mises equivalent stress powered by $m$. Both results have similar pattern as von Mises stress contour in Figure 12.

The final calculations performed inside ANSYS are to determine $X_{v a r}$ and $Y_{v a r}$ as defined in Equations 9 and 10. Both parameters are shown in Figure 16 and 17, respectively. The contour plots of $X_{v a r}$ and $Y_{v a r}$ has maximum values at Tip 1 and minimum values at Tip 2 similar to that of von Mises stress as both parameters directly related to von Mises equivalent stress

The next step is performed in MATLAB as follows. New functions $x=\ln ($ Xvar) and $\mathrm{y}=-\ln$ (Yvar) are defined, where values of $X_{v a r}$ and $Y_{v a r}$ are imported from ANSYS. Values of $y$ as function of $x$ are mapped in Figure 18. Each point in the graph in Figure 18 represents $X_{\text {var }}$ and $Y_{\text {var }}$ for one adhesive element. The scatter in the points is due to the fact that different combinations of $\Delta \sigma_{e q}^{2} R_{v}$ could produce the same $X_{V A R}$ but different values of $Y_{V A R}$, which is equal to $N_{f} \Delta \sigma_{e q}^{m}$. Based on linear regression of map of $x$ and $y$ values obtained from finite element analysis given in Figure 18, two constants, $C_{1}$ and $C_{2}$ have been found. Because both of these constants are directly related to the damage parameters in equations 11 and $12, A$ and $\beta$ can be determined. 
To identify map of $y$ function of $x$ near singularity point (Tip 1), several paths have been defined as shown in Figure 19. The results for these paths are shown in Figure 20 and compared to the zoomed data in Figure 18.

Using the same procedure, damage parameters $A$ and $\beta$ can be found for other load level. The results are listed in Table 2 . The number of cycles to failure $\left(N_{f}\right)$ listed in the last column of Table 2 is calculated using the damage model (equation 6) to validate the derivation of the damage parameters $A$ and $\beta$. This value is averaged from $N_{f}$ of all adhesive elements. Both damage parameters $A$ and $\beta$ are plotted as a function of applied load level (represented by $\Delta \sigma_{e q}^{*}$, von Mises stress range at stabilization of harding or at undamaged state) as shown in Figures 21 and 22, respectively. Both Figures show that damage parameters $A$ and $\beta$ have tendency to increase, as $\Delta \sigma_{e q}^{*}$ increases.

Comparing the results in Figures 21 and 22 to those obtained for bulk adhesive in part 1 of this paper, it can be seen that the damage parameters obtained from the single lap joints are different from those obtained from bulk adhesive. This is mainly due to the multi-axial stress state in the adhesive in the single lap joint, which leads to different triaxiality functions distributed along the adhesive layer (Figure13).

\section{Conclusions}

The fatigue damage parameters A and $\beta$ of SLJ cannot be directly related to those obtained from bulk adhesive test (see Part I of this paper). This is because the load level in bulk adhesive is directly related to von Mises equivalent stress and the triaxiality function is constant and equal to unity. Whereas the load level in the single lap joint is 
not directly related to von Mises equivalent stress due to the multi-axial state of stress in the adhesive layer, giving a range of triaxiality function along the adhesive layer.

It was found from the triaxiality contour of the SLJ that its values vary from an average minimum of 1 to an average maximum of 3.85 at singularity tip. The triaxiality function of SLJ is difficult to control along the adhesive layer and varies significantly. Future works is required in order to consider other types of adhesive joints that can be implemented at experimental level and that can produce a triaxiality function, which can be controlled. This has been the topic of further research works by the authors.

\section{References}

1. O. Volkersen, Die Nietkraftverteilung in Zugbeanspruchten Nietverbindungen mit Konstanten Laschen-querschnitten, Lutfahrtforschung 15, 4 (1938).

2. M. Goland, and E. Reissner, J. Appl. Mech., 11, A17 (1944).

3. L.J. Hart Smith, Adhesive-Bonded Double-Lap Joints, Technical Report, NASA (1973).

4. Y. Frostig, O.T. Thomsen and F. Mortensen, Journal of Engineering Mechanics, 125 (1999).

5. B. Duncan and L. Crocker, Measurement Good Practice Guide No. 45 Characterisation of Flexible Adhesives for Design, NPL Materials Centre, National Physical Laboratory (2000).

6. A.G. Magalhaes, M.F.S.F. de Moura and J.P.M. Goncalves, Int. Journal of Adhesion \& Adhesives, 25, 313 (2005).

7. R.D. Adams and N.A. Peppiatt, Journal of Strain Analysis, 9, 185 (1974). 
8. J. Liu and T. Sawa, J. Adhesion Sci. Technol., 14, 67 (2000).

9. J.P.M Goncalves, M.F.S.F. de Moura, A.G. Magalhaes and P.M.S.T. de Castro, Fatigue Fracture Eng. Mat. Structure, 26, 479 (2002).

10. A.D. Crocombe, How to Tackle Non-linear Finite Element Analysis, NAFEM Ltd (2001).

11. M.M. Abdel Wahab, J. Adhesion Sci. Technol., 14, 851 (2000).

12. M.M. Abdel Wahab, I.A. Ashcroft, A.D. Crocombe and P.A. Smith, International Journal of Fatigue, 24, 705 (2002).

13. G. Dean and L. Crocker, The Use of Finite Element Methods for Design with Adhesives, Measurement Good Practice Guide No. 48, Materials Centre National Physical Laboratory (2001).

14. L. Greenwood, T.G. Boag and A.S. McLaren, Stress distribution in lap joints, Adhesion: Fundamental and practice, McLaren (1969).

15. S.J. John, A.J. Kinloch and F.L. Matthews, Composites, 22, 121 (1991).

16. A.D. Crocombe, G. Richardson and P.A. Smith, J. Adhesion, 42, 209 (1993).

17. G.P. Anderson and K.L. DeVries, Intl. J. Fracture, 39, 191 (1989).

18. H.L. Groth and I. Brottare, J. of testing and evaluation, 291 (1988).

19. T. Hattroi, S. Sakata and G. Murakami, J. of Electronic Packaging, 111, 234 (1989).

20. D.R. Lefebvre and D.A. Dillard, J. Adhesion, 70, 119 (1999).

21. Z. Wu, Composite Structures, 65, 339 (2004).

22. A.R. Akisanya and C.S. Meng, Journal of the Mechanics and Physics of Solids, $51,27(2003)$. 
23. L. R. Xu, S. Sengupta and H. Kuai, International Journal of Adhesion and Adhesives, 24, 455 (2004) .

24. Material Reference, ANSYS ver. 9.0 (2008).

25. A.G. Solana, Fatigue Initiation In Adhesively Bonded Joints, PhD Thesis, University of Surrey, (2008).

26. J.R. Barber, Solid Mechanics and Its application, Elasticity, 2nd Edition, Kluwer Academic Publishers (2002).

27. S.I. Krishnamachari, Applied Stress Analysis of Plastics: A mechanical engineering approach, Van Nostrand Reinhold (1993).

28. M.M. Abdel Wahab, I.A. Ashcroft, A.D. Crocombe and S.J. Shaw, Journal of Adhesion Science Technology, 15, 763 (2001).

29. J. Lemaitre, A Course on Damage Mechanics, New York: Springer-Verlag (1996).

30. A.G. Varias, Z. Guo and C.F. Shih, J. Mech. Phys. Solids, 39, 963 (1991).

31. Y. Huang, K.X. Hu, C.P. Yeh, N.Y. Li, K.C. Hwang, Journal of Electronic Packaging, 118, 229 (1996). 
Table 1: Single lap joint fatigue test results [25]

\begin{tabular}{|c|r|r|r|c|}
\hline Load level \% & & & & \\
& Min Load $(\mathrm{kN})$ & Max Load $(\mathrm{kN})$ & $\begin{array}{c}\text { Number of cycles } \\
\text { to failure }\left(\mathrm{N}_{\mathrm{f}}\right)\end{array}$ & Failure Strain \\
\hline $30 \%$ & 0.334 & 3.34 & 233007 & 0.000835 \\
\hline $40 \%$ & 0.456 & 4.56 & 73364 & 0.001086 \\
\hline $50 \%$ & 0.57 & 5.71 & 14175 & 0.001303 \\
\hline $60 \%$ & 0.64 & 6.4 & 4297 & 0.002046 \\
\hline
\end{tabular}

${ }^{+}$Percentage of static failure load

Table 2: Summary of damage parameters from linear regression for different load level. $\Delta \sigma_{e q}^{*}$ is the von-Mises stress range at stabilization harding or undamaged state.

\begin{tabular}{|c|c|c|c|c|c|c|c|c|}
\hline$\Delta \sigma_{e q}^{*}$ & $\mathrm{R}_{\mathrm{v}}$ & $\begin{array}{c}\text { Load } \\
\text { level } \\
\%^{+}\end{array}$ & $\begin{array}{c}\quad N_{f} \\
\text { experiment }\end{array}$ & $C_{1}$ & $C_{2}$ & $\beta$ & $A$ & $\begin{array}{c}\quad N_{f} \\
\text { calculated }\end{array}$ \\
\hline 17.081 & 1.56 & 30 & 233007 & $\begin{array}{r}- \\
12.359\end{array}$ & $-3.72 \times 10^{-2}$ & $-7.44 \times 10^{-2}$ & $4.27 \times 10^{-6}$ & 233112 \\
\hline 21.807 & 1.59 & 40 & 73364 & $\begin{array}{r}- \\
11.208\end{array}$ & $-3.65 \times 10^{-2}$ & $-7.30 \times 10^{-2}$ & $1.35 \times 10^{-5}$ & 73350 \\
\hline 25.575 & 1.63 & 50 & 14175 & -9.569 & $-3.58 \times 10^{-2}$ & $-7.16 \times 10^{-2}$ & $6.92 \times 10^{-5}$ & 14178 \\
\hline 27.522 & 1.65 & 60 & 4297 & -8.379 & $-3.53 \times 10^{-2}$ & $-7.06 \times 10^{-2}$ & $2.27 \times 10^{-4}$ & 4297 \\
\hline
\end{tabular}

${ }^{+}$Percentage of static failure load 


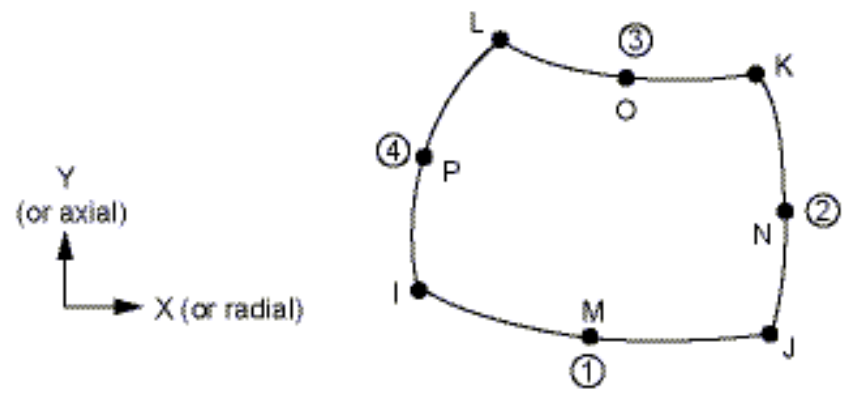

(a)

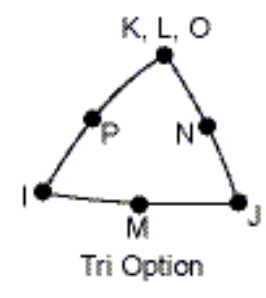

(b)

Figure 1: Plane82 geometry, (a) general 8-noded element, (b) triangular option

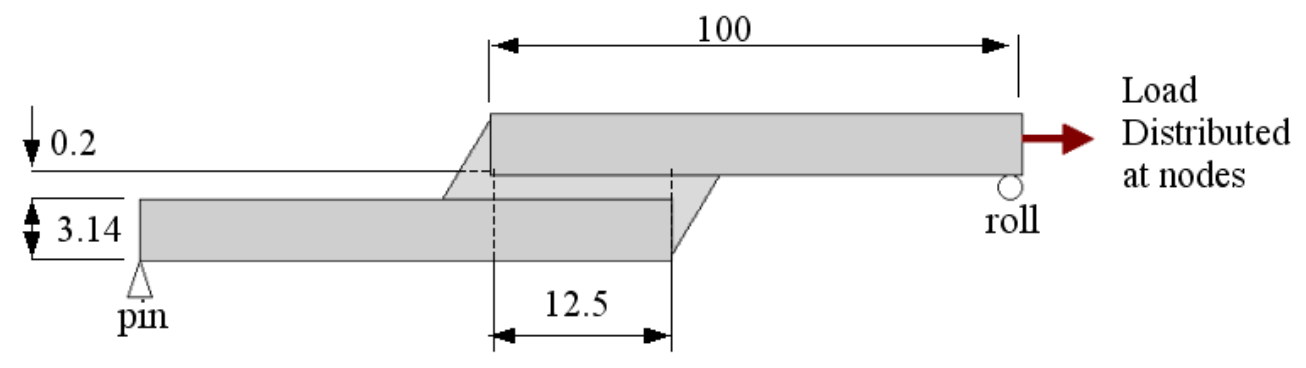

Figure 2: Geometry of single lap joints with boundary conditions (dimensions in $\mathrm{mm}$ )

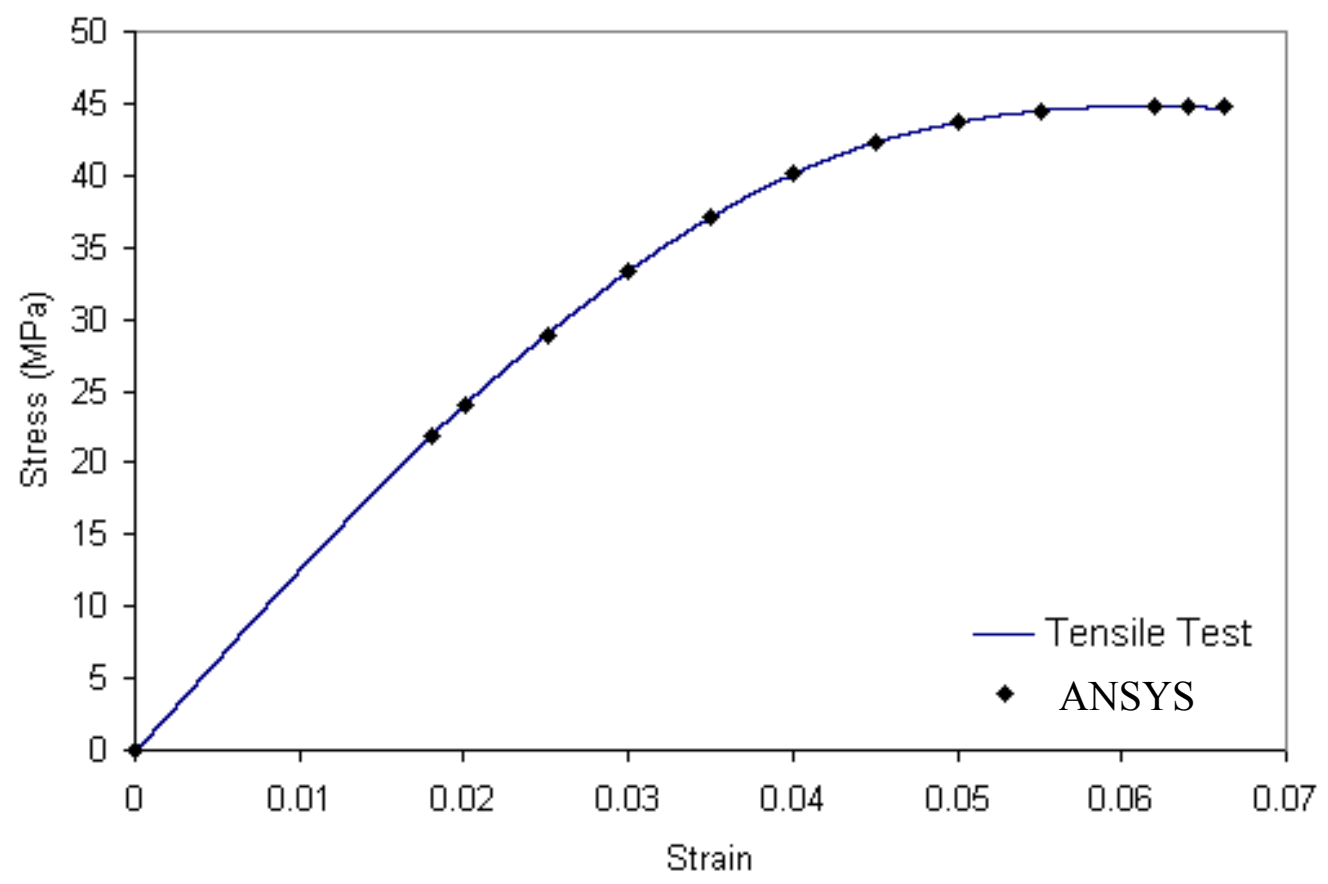

Figure 3: Comparison between tensile test and ANSYS input material data 


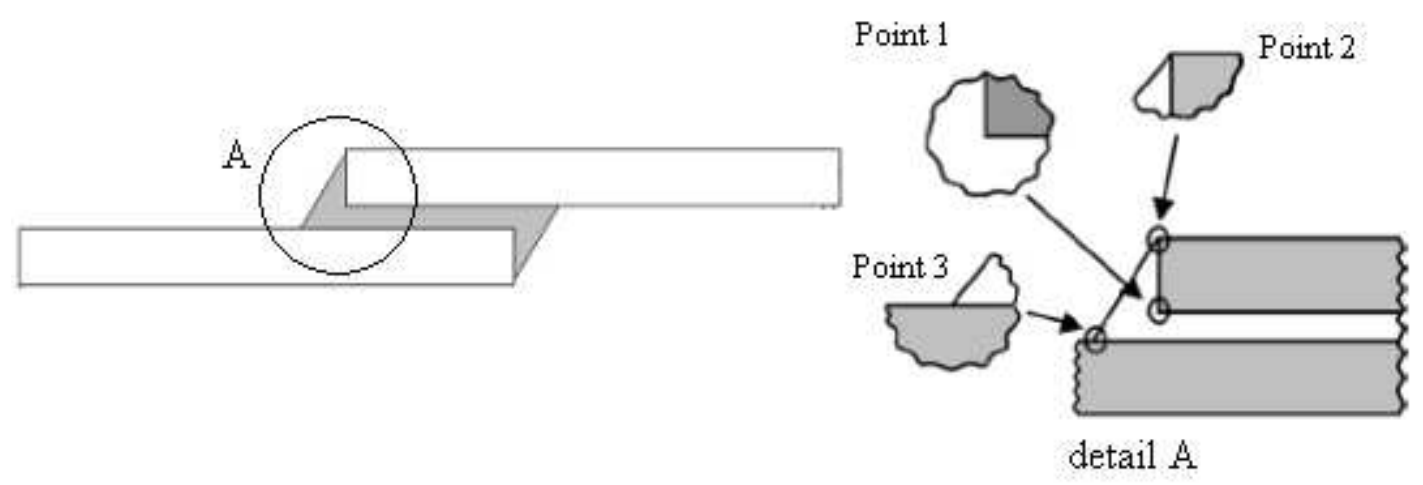

Figure 4: Points of stress singularity in a single lap joint; (a) Global view, (b) Zoom at overlap edge

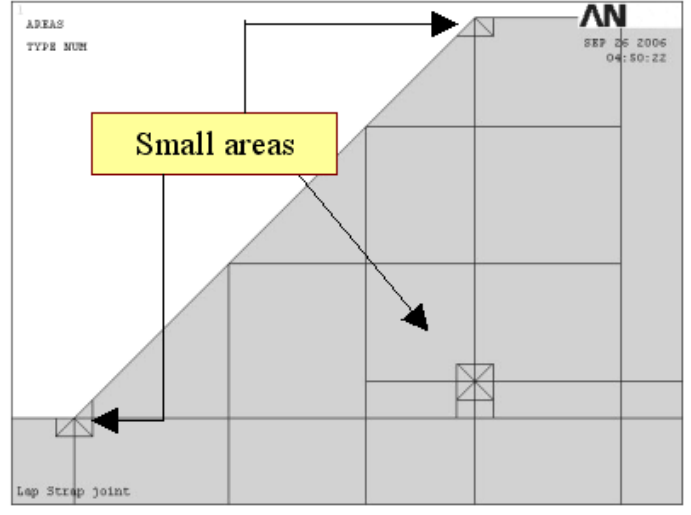

(a)

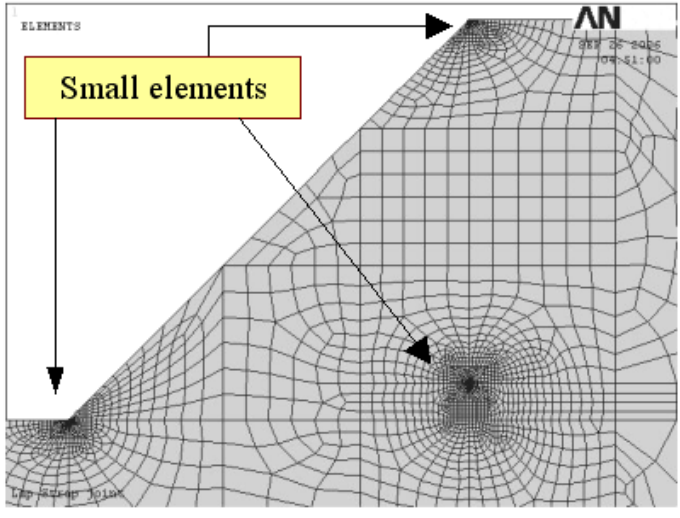

(b)

Figure 5: (a). Areas where the finest meshing size are located

(b) Final Meshing 


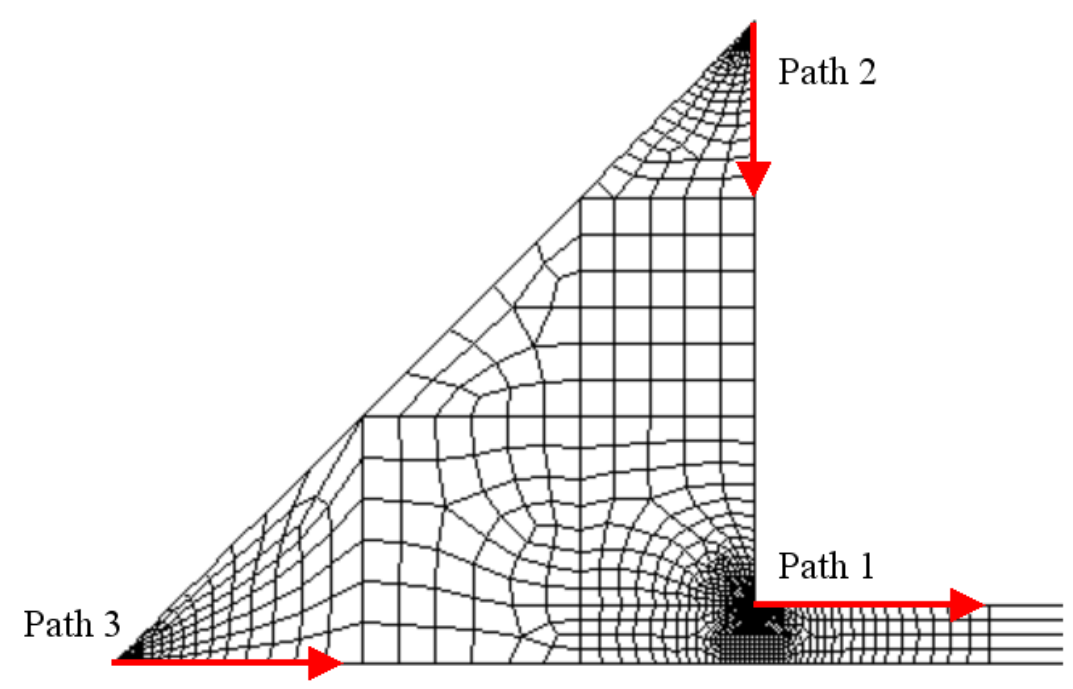

Figure 6: Paths to study convergence at singularity tips

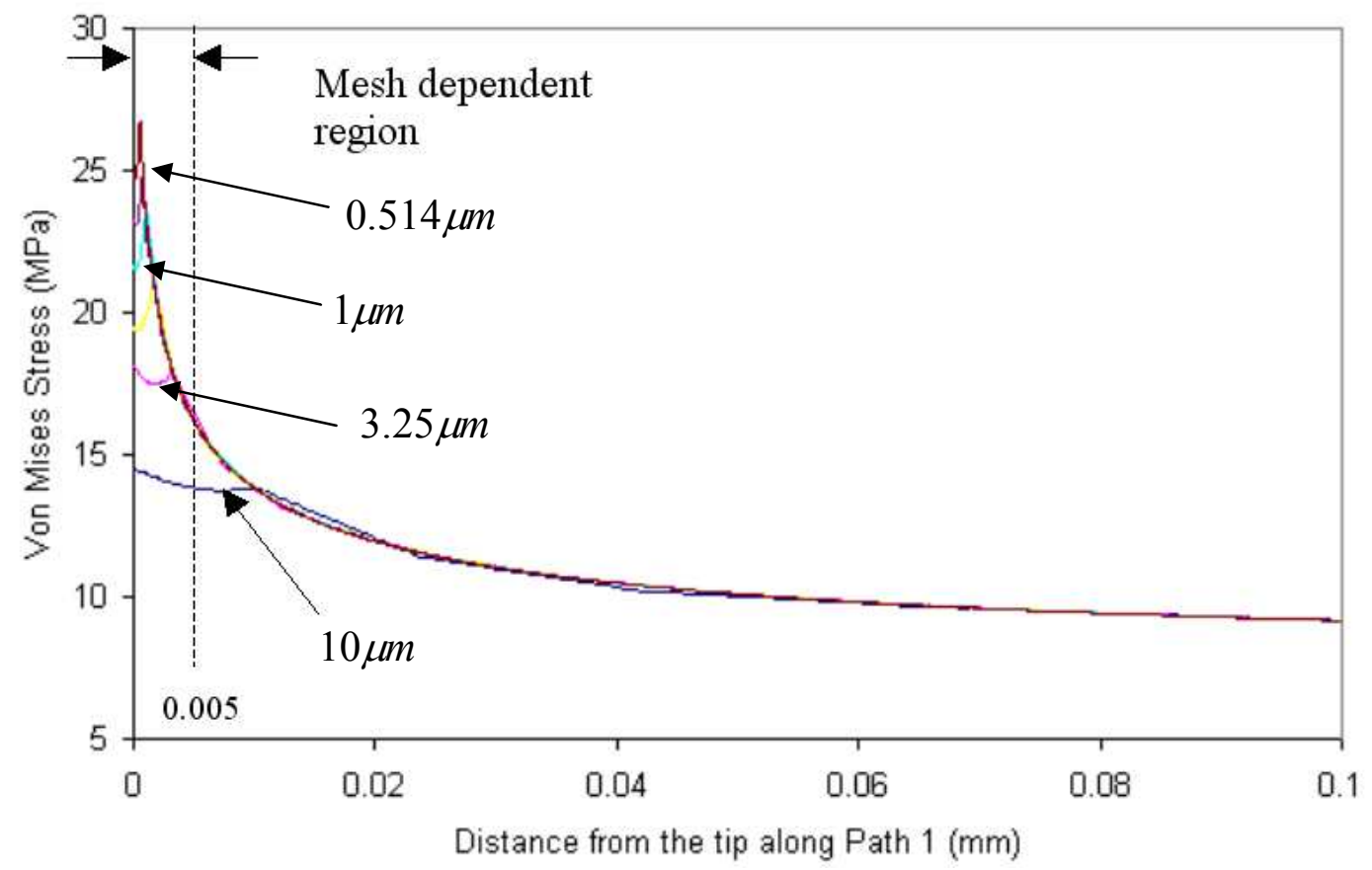

Figure 7: Comparison of von Mises stresses for Path 1 for different element sizes at crack tip - tension load $1 \mathrm{kN}$ 


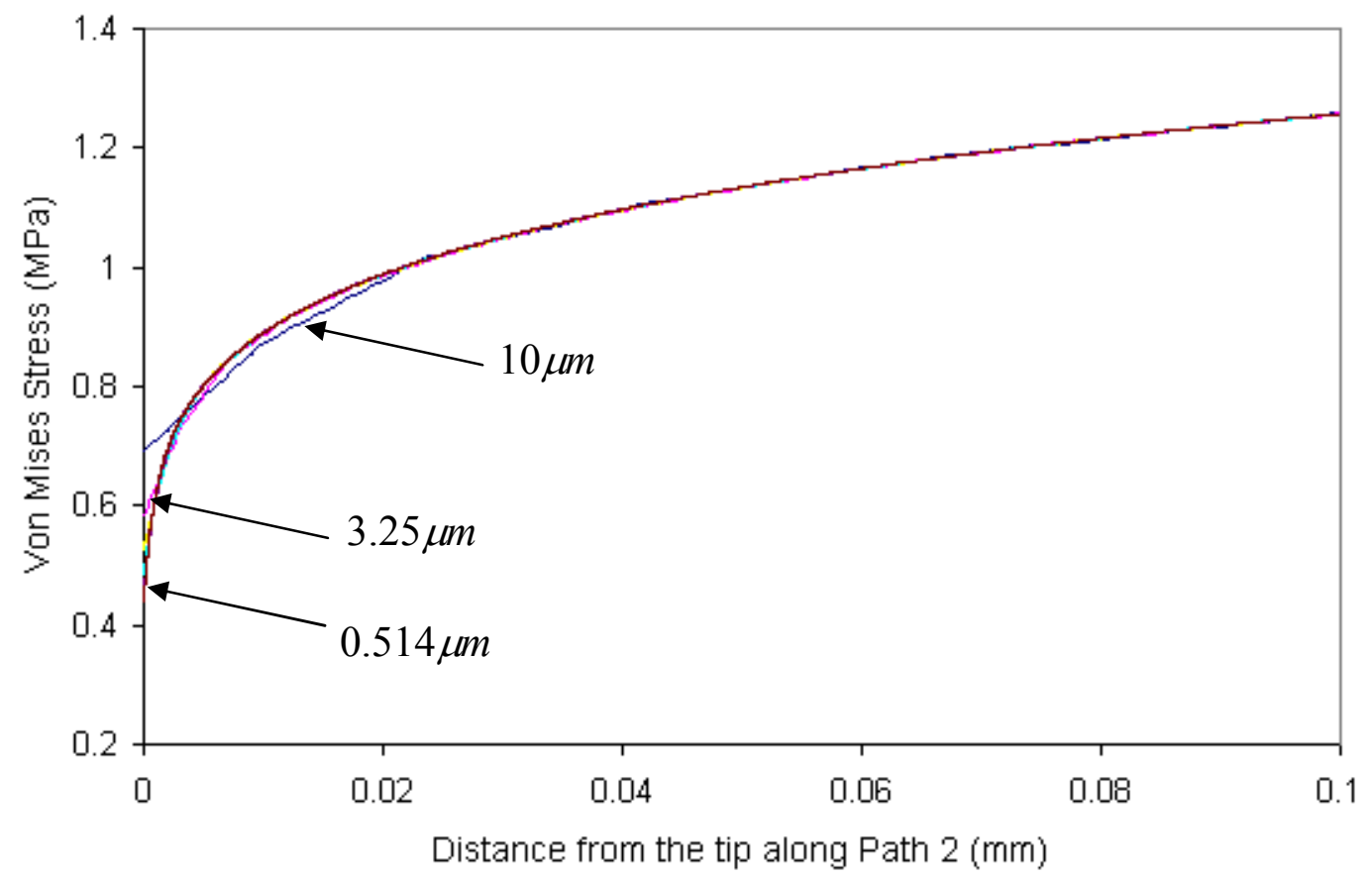

Figure 8: Comparison of von Mises stresses for Path 2 for different element sizes at crack tip - tension load $1 \mathrm{kN}$

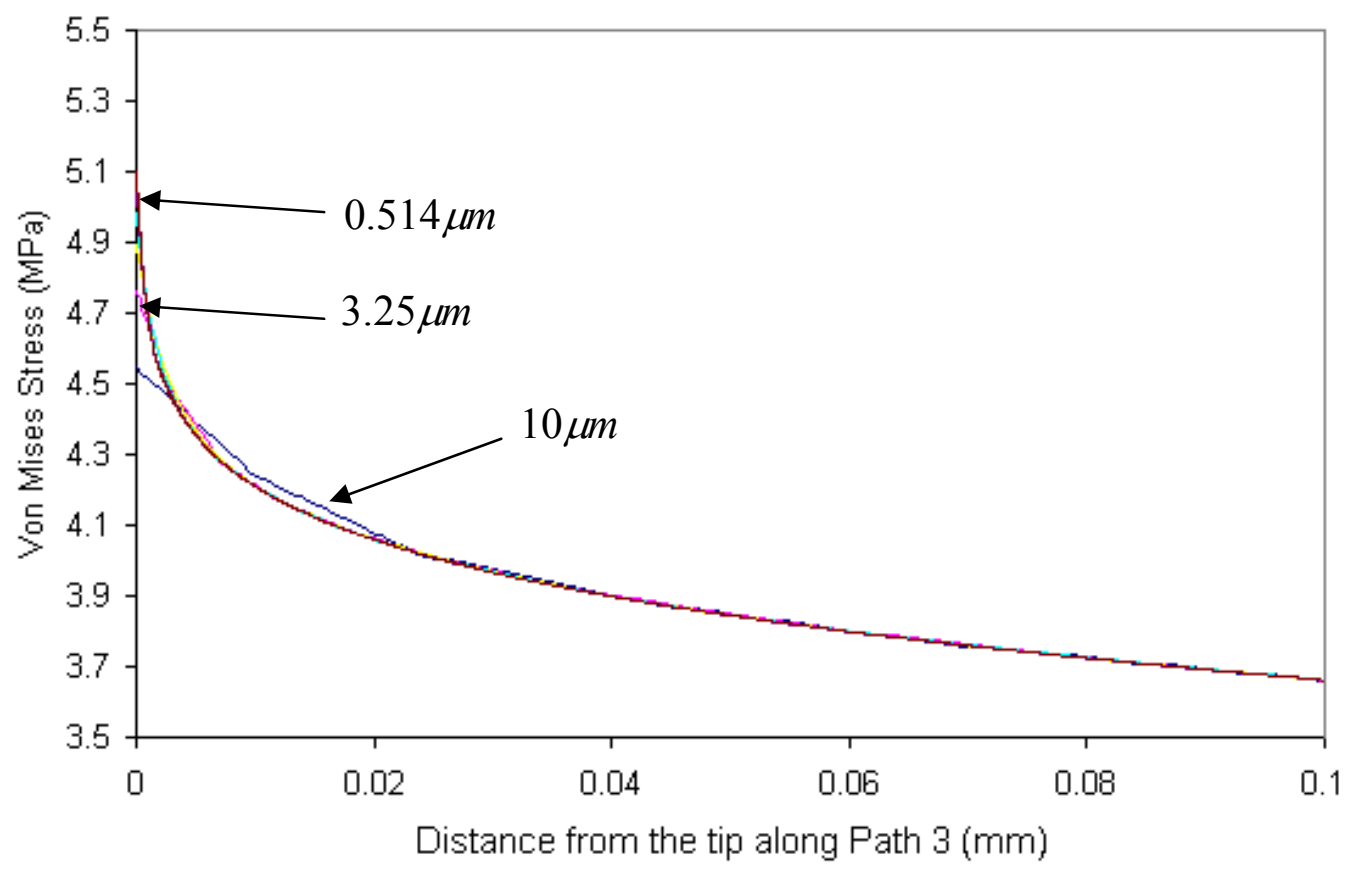

Figure 9: Comparison of von Mises stresses for Path 3 with tension load $1 \mathrm{kN}$ 


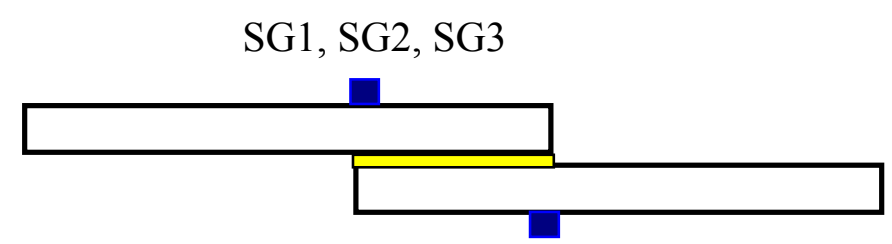

SG4, SG5, SG6

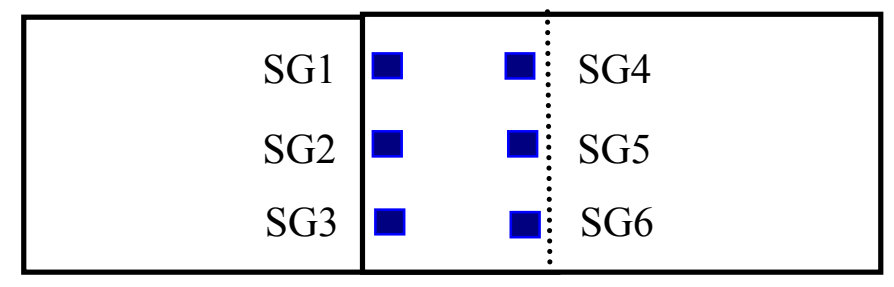

(a)

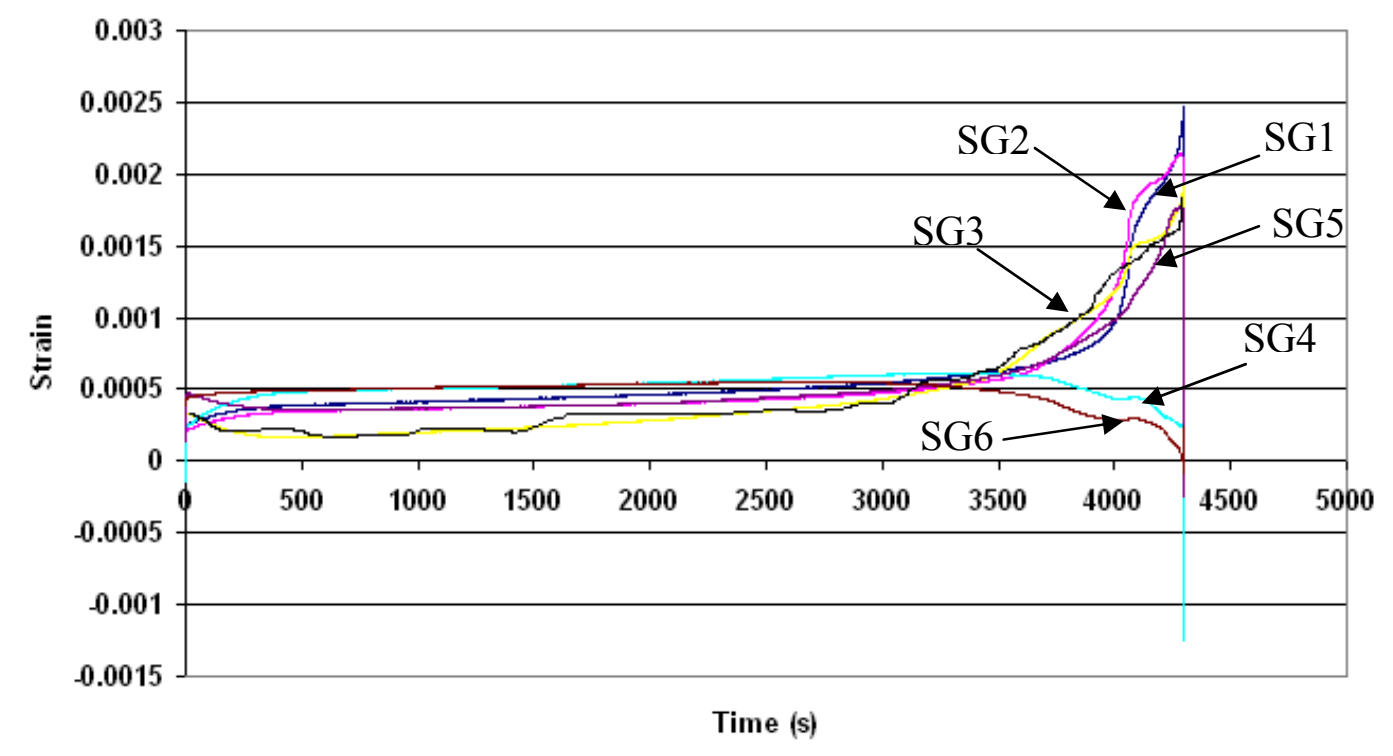

(b)

Figure 10: Experimental strain measurement, (a) strain gauges position, (b) strain as a function of number of cycles at load level of $60 \%$ of static failure load [25] 


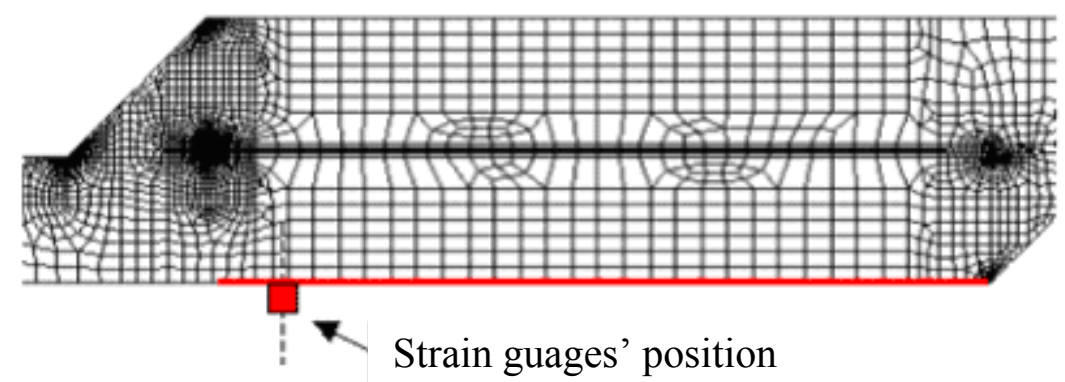

(a)

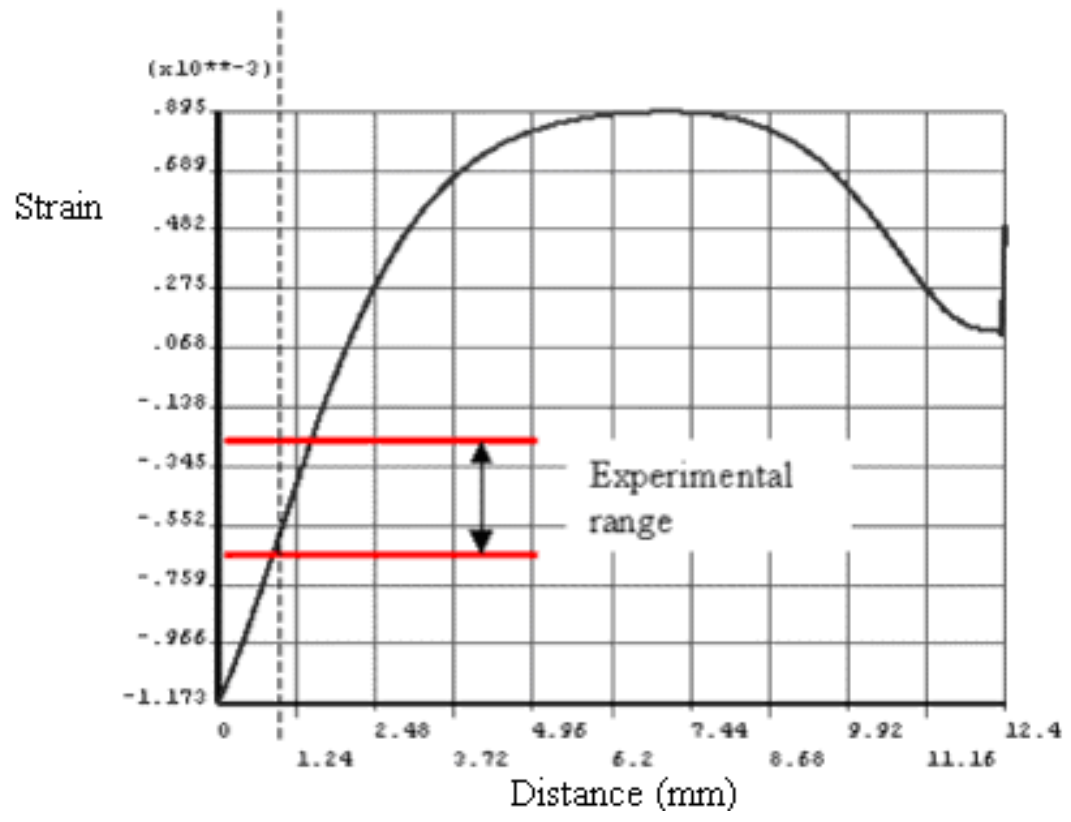

(b)

Figure 11: Validation of finite element analysis; (a) strain gauge position and (b) strain distribution from FEA compared to experimental strain range 


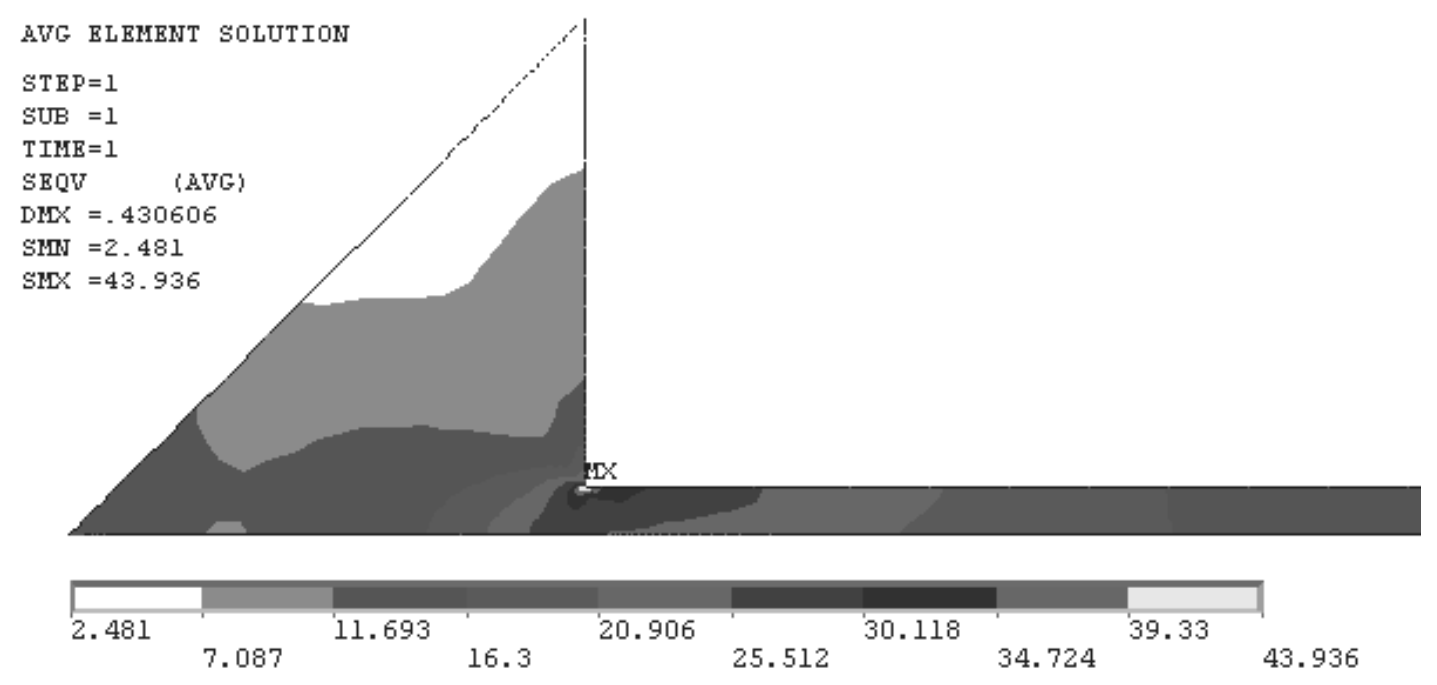

Figure 12: Contour of von Mises equivalent stress in MPa at load level 30\% of static failure load

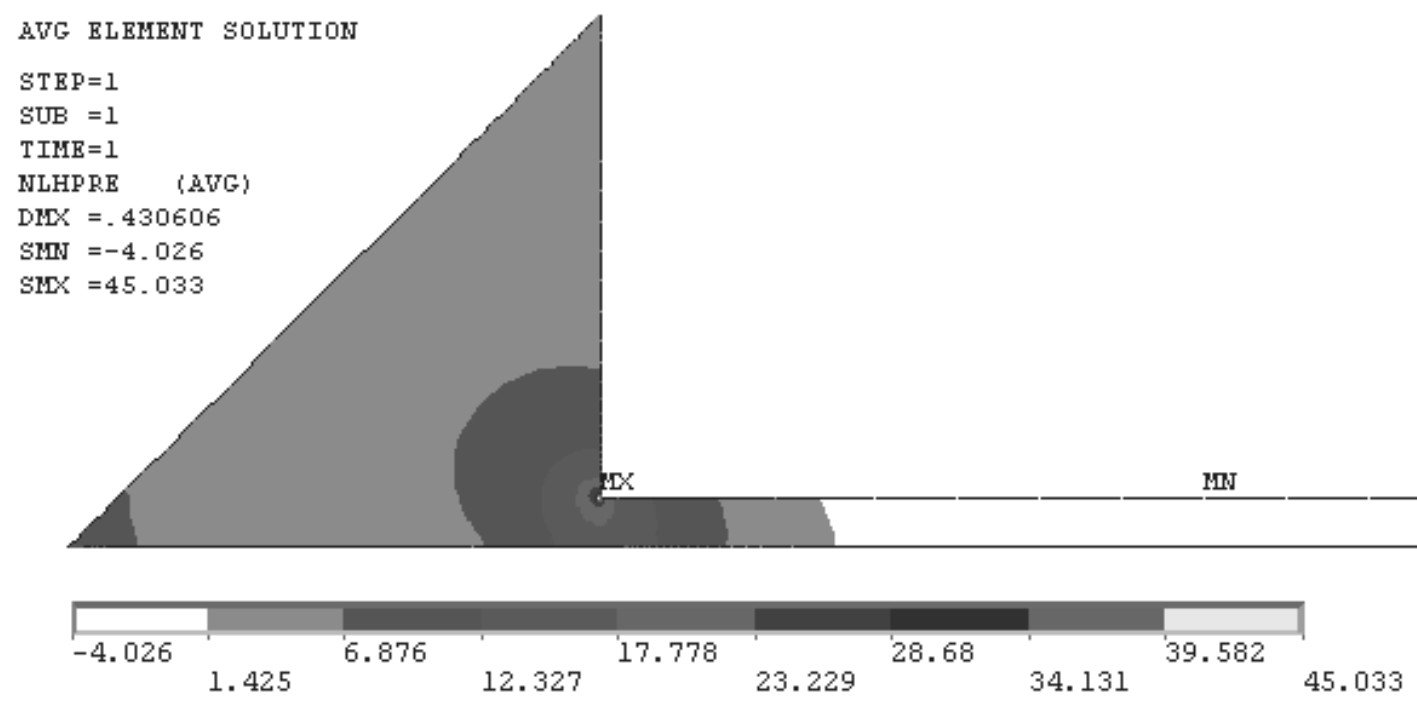

Figure 13: Contour of hydrostatic stress in MPa at load level 30\% of static failure load 


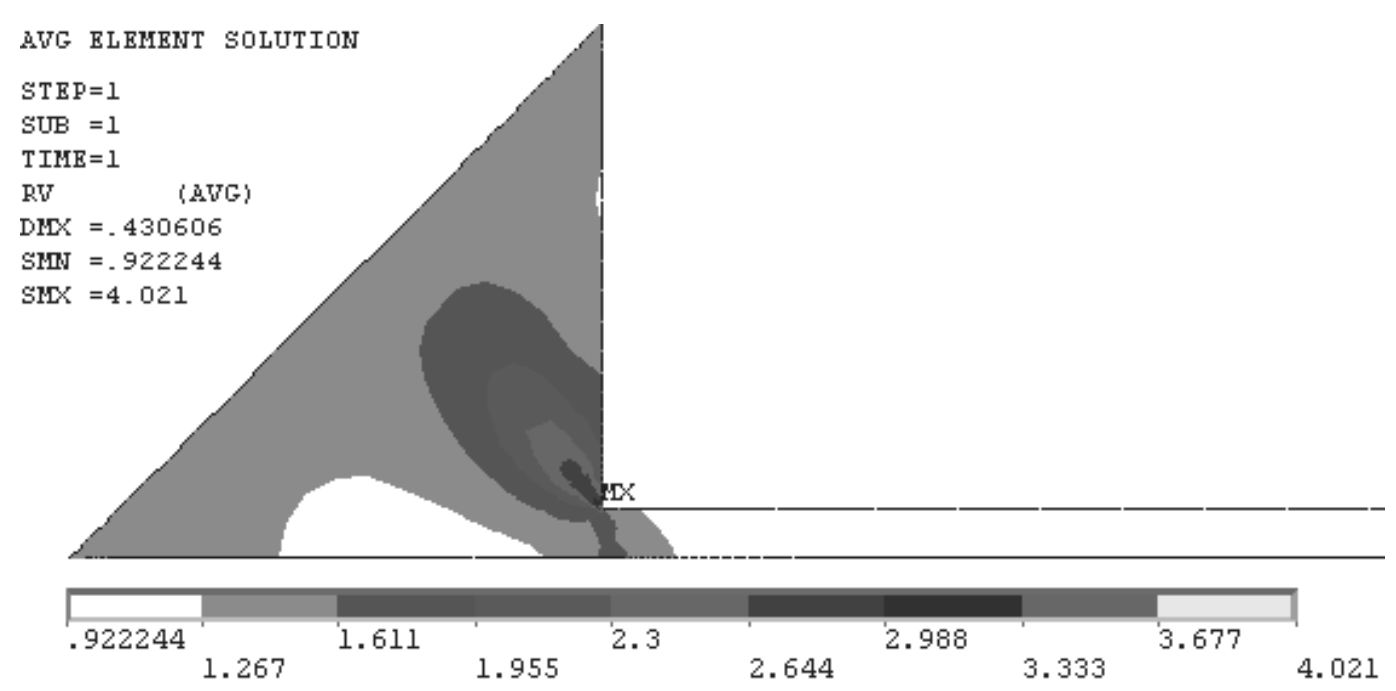

Figure 14: Contour of function of Triaxiality $\left(\mathrm{R}_{\mathrm{V}}\right)$ at load level $30 \%$ of static failure load 


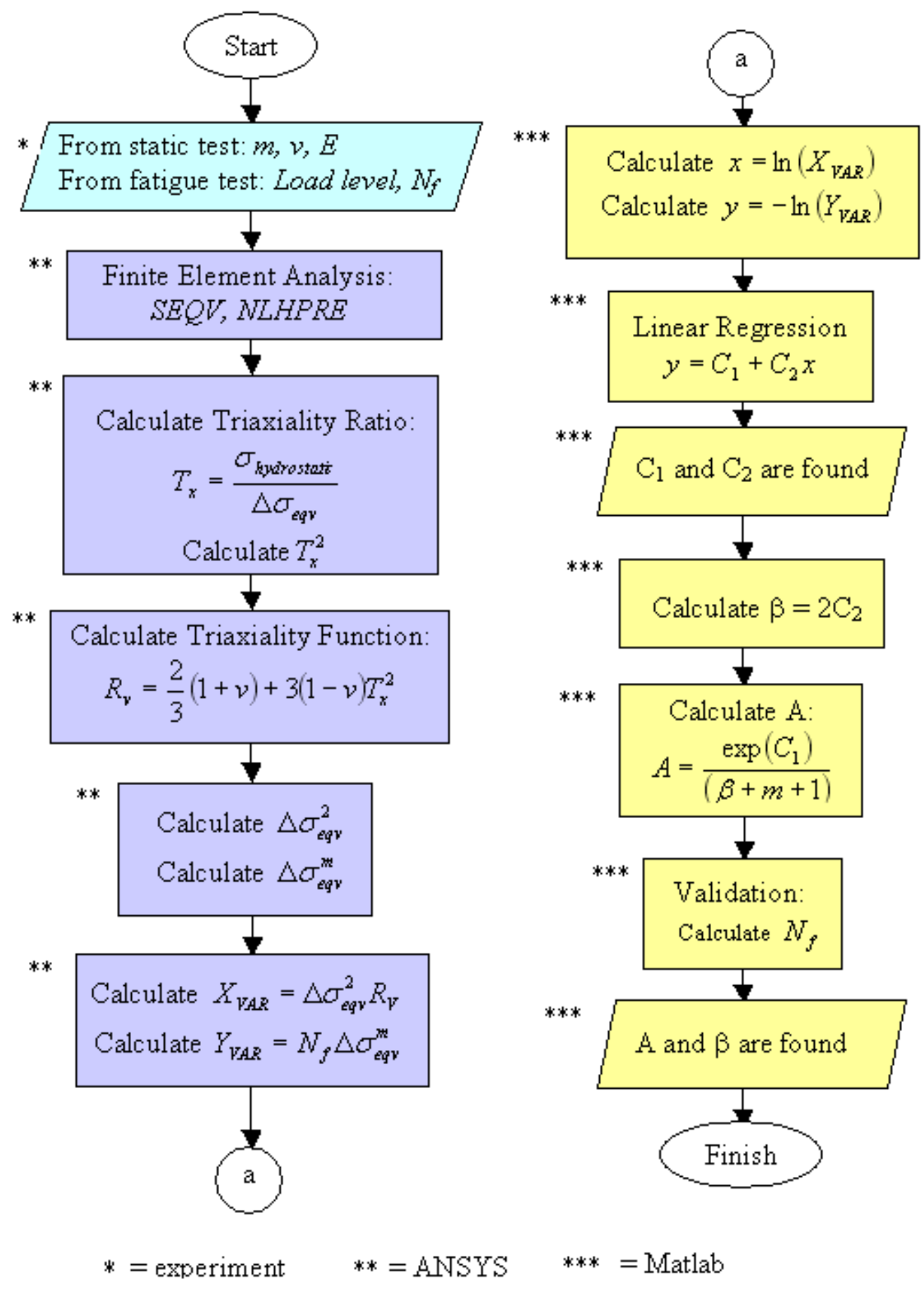

Figure 15: Damage parameters calculation flow chart 


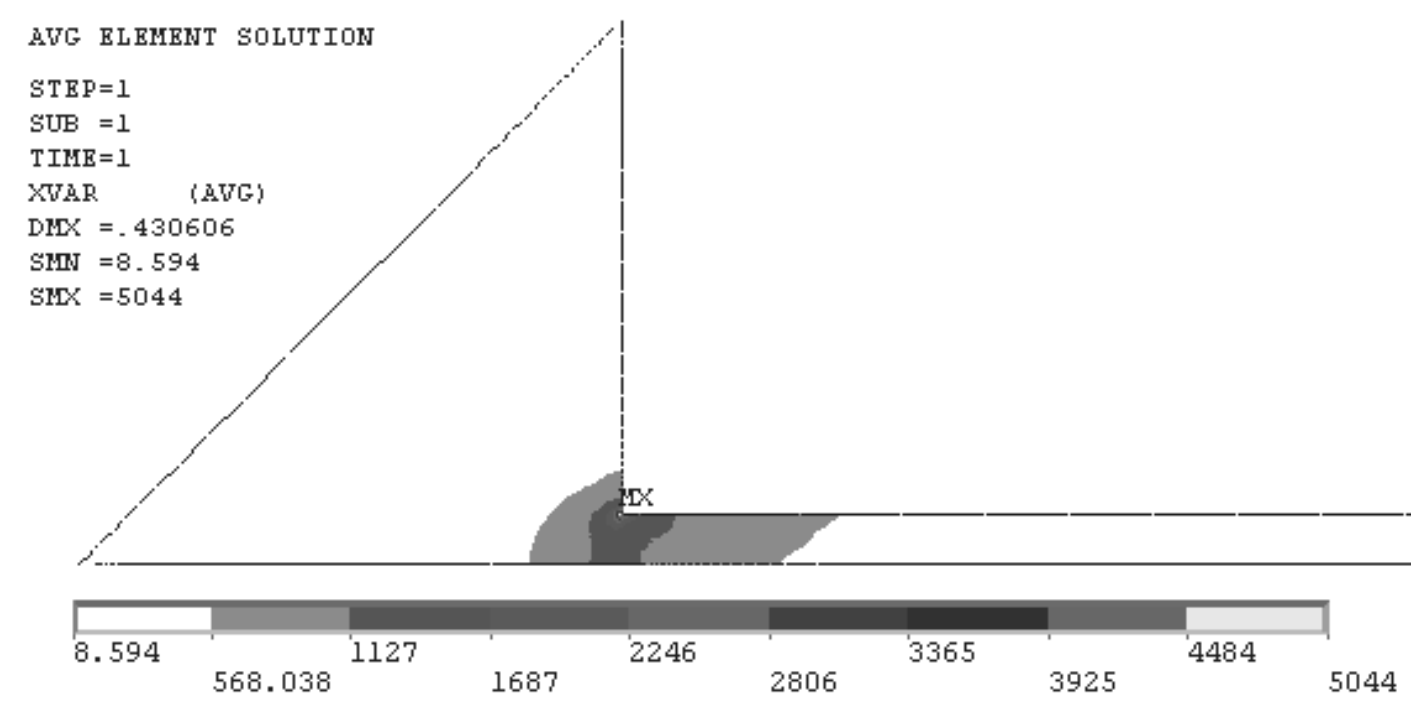

Figure 16: Contour of $X_{v a r}\left(X_{V A R}=\Delta \sigma_{e q}^{2} R_{v}, \Delta \sigma_{e q}\right.$ in MPa) at load level 30\% of static failure load

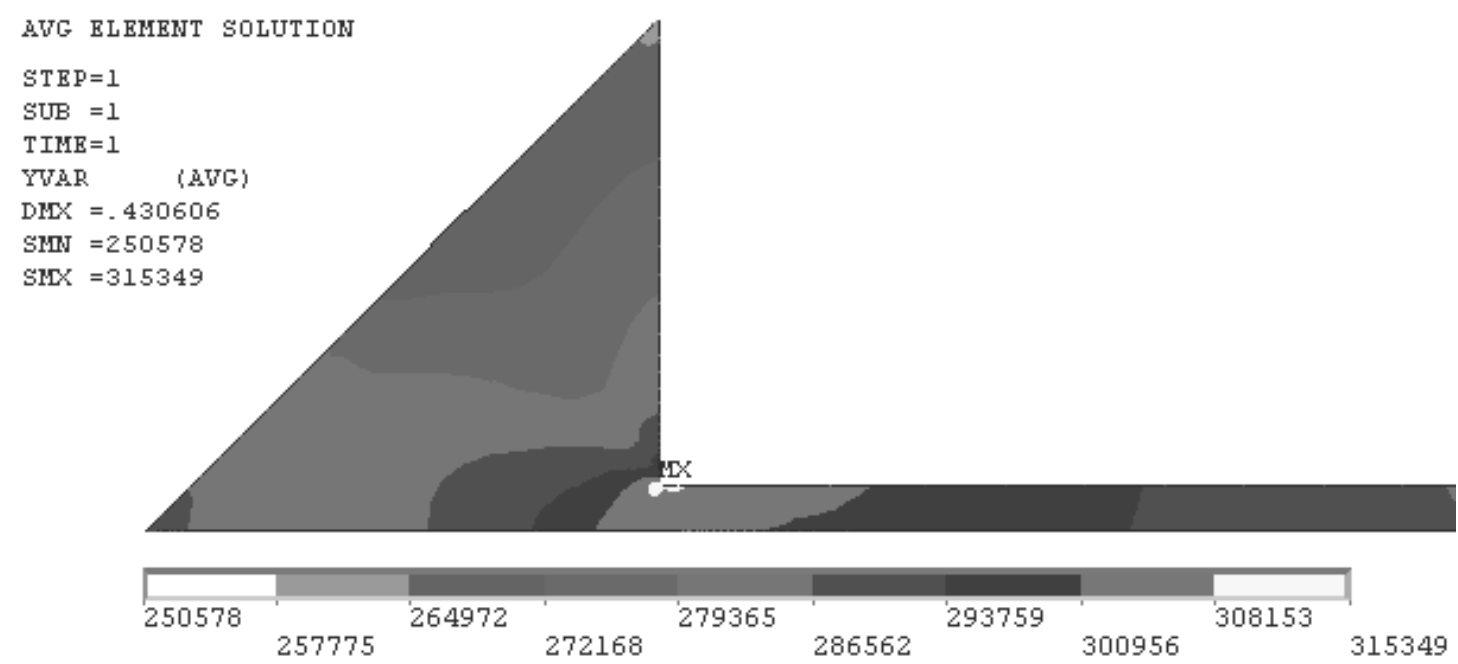

Figure 17: Contour of $Y_{v a r}\left(Y_{V A R}=N_{f} \Delta \sigma_{e q}^{m}, \Delta \sigma_{e q}\right.$ in MPa $)$ at Load Level 30\% of static failure load 


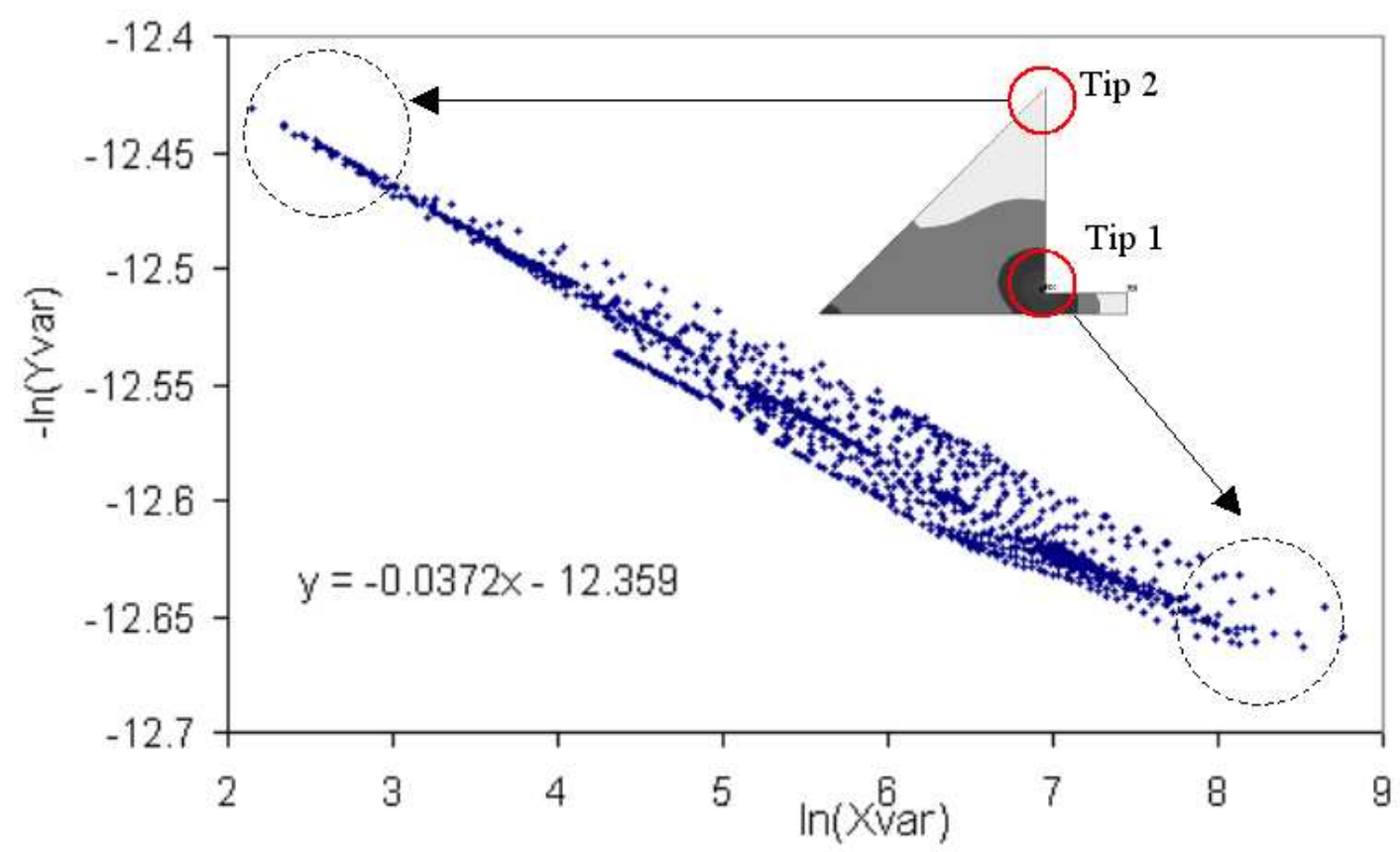

Figure 18: Map of $y(-\operatorname{Ln}(Y V A R))$ values function of $x(\operatorname{Ln}(X V A R))$ values and linear regression at load level $30 \%$ of static failure load

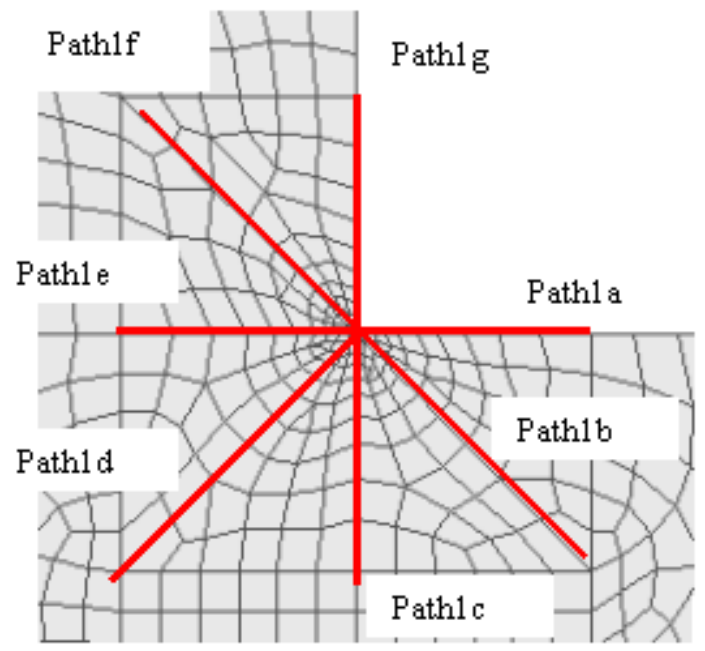

Figure 19: Paths definition near singularity (Tip 1) 


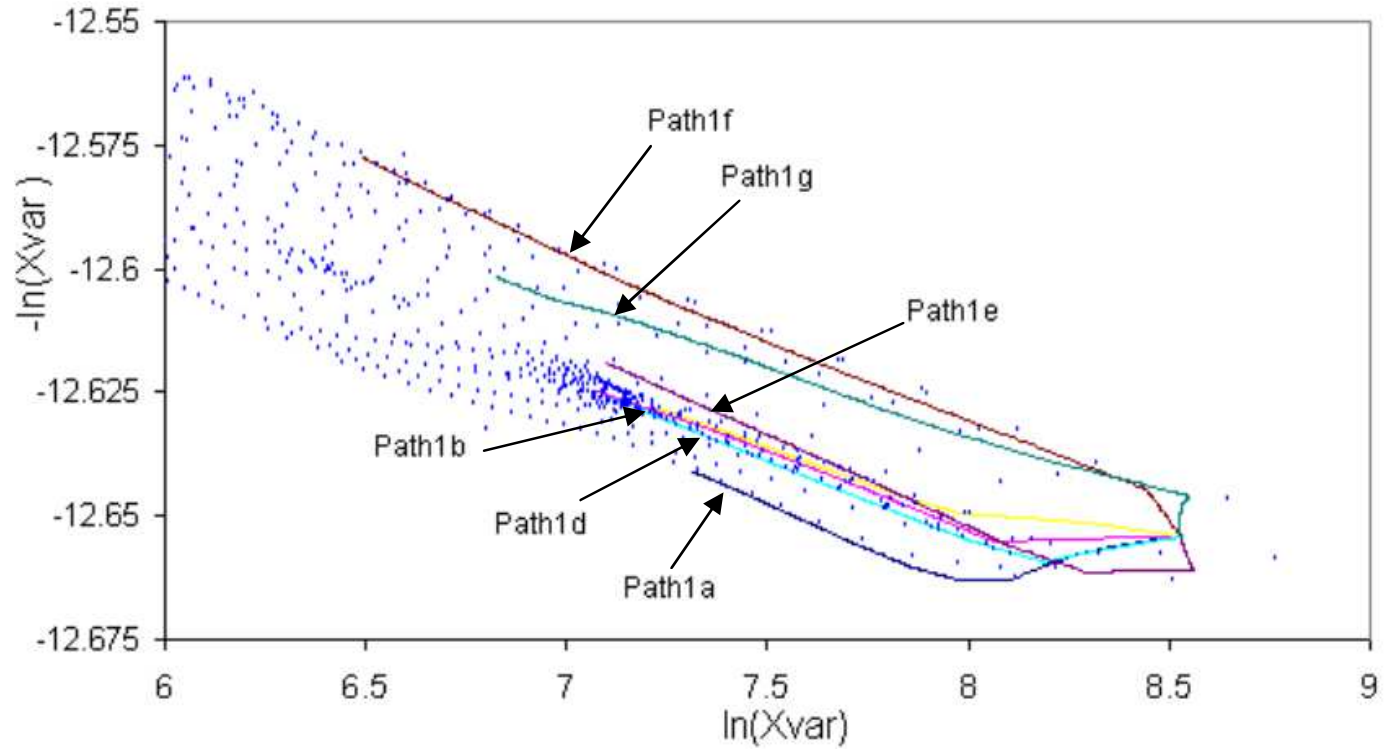

Figure 20: Details of $y(-\operatorname{Ln}(Y V A R))$ values function of $x(\operatorname{Ln}(X V A R))$ values near point of singularity (Tip 1) 


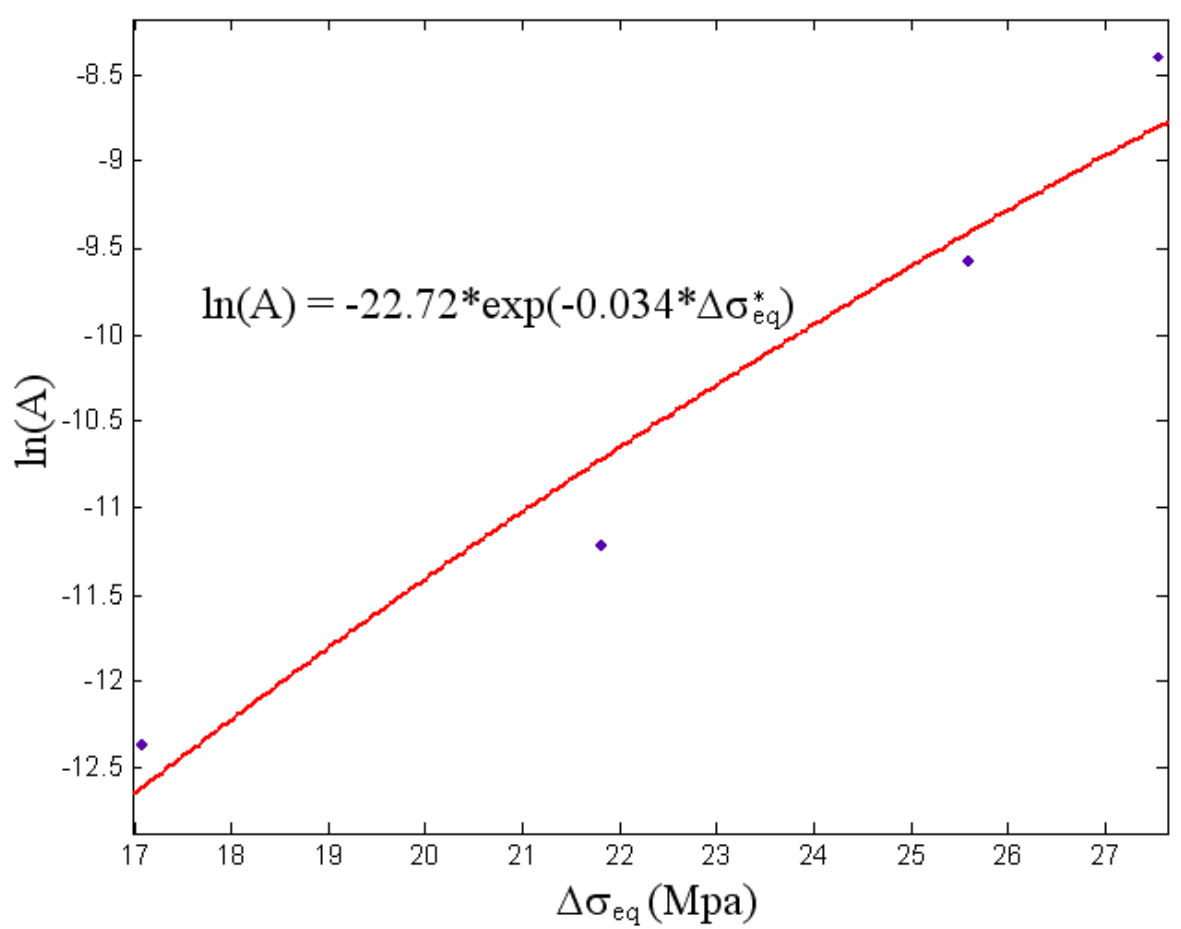

Figure 21: Damage parameter A function of stress range $\Delta \sigma_{e q}^{*}$

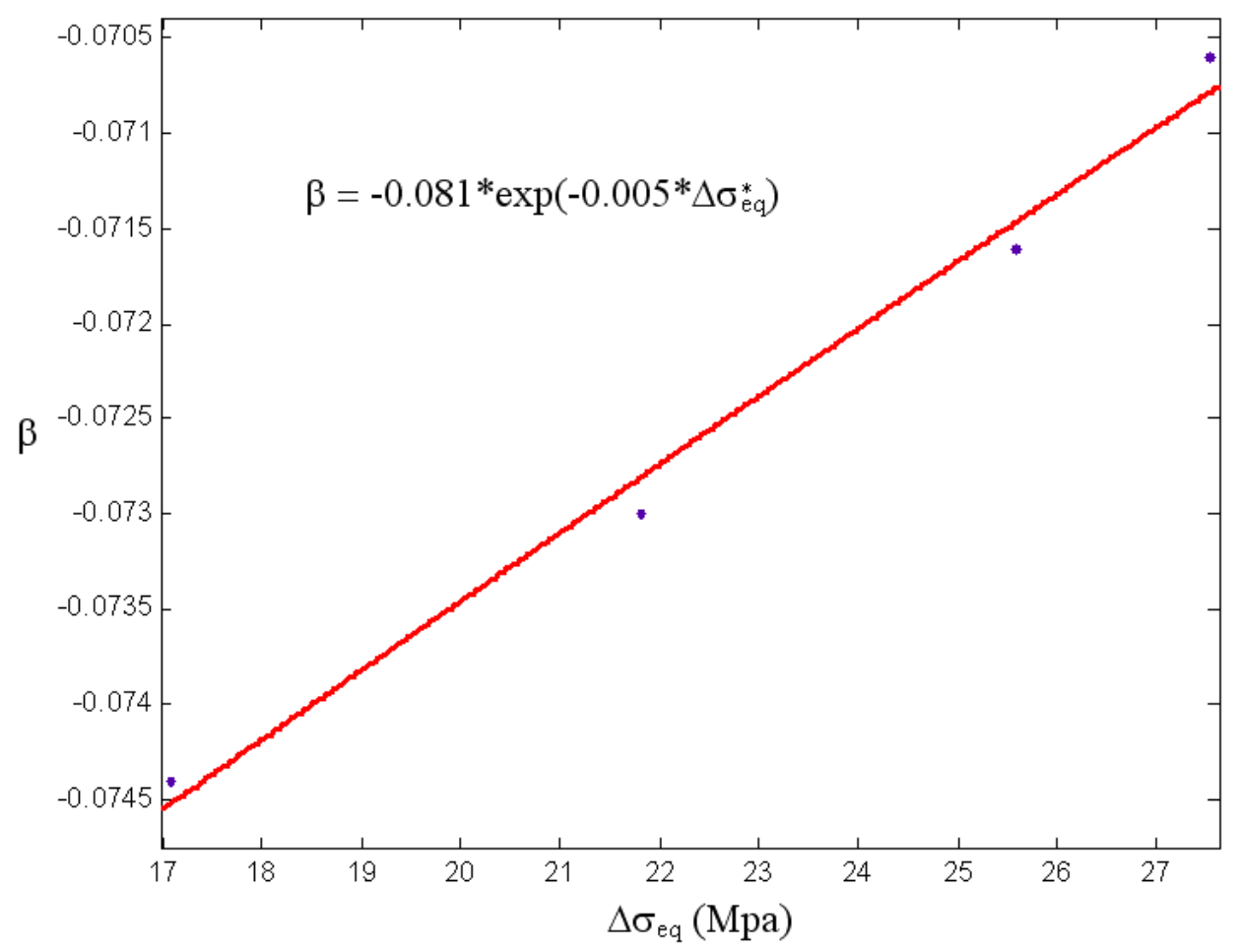

Figure 22: Damage parameter $\beta$ function of stress range $\Delta \sigma_{e q}^{*}$ 